\title{
Transformation of the justification of modern political processes at the national and international level: the challenge of time
}

\author{
V. I. Kamyshanov ${ }^{1}$
}

${ }^{1}$ School of political studies, RANEPA, 82 Vernadsky Ave., Moscow 119571, Russian Federation

DOI: $10.18255 / 2412-6519-2020-3-230-237$

Research Article Full text in Russian

The article deals with the search for new directions of theoretical understanding and practical justification of modern political processes at the national and international level. Based on a comparison of the Russian and American approaches to assessing the development of political science, a line is drawn to study the prospects for their conjunction and adaptation to new conditions. The article considers the need to apply time-defying approaches to the development of theoretical directions of modern political science, with the definition of criteria for the depth of transformation of structural conditions, as well as factors of divergence of these conditions that affect the change in the nature and form of political power in the modern world. The relevance of this approach is confirmed by a comparative analysis of existing assessments by researchers of the development of political processes at the national level under the influence of new challenges to political stability as a key factor in global security. The prospects for developing new approaches correlate with the crisis phenomena in the development of international relations and the formation of contradictions in the dichotomy-confrontation - cooperation. This state determines the content of the considered points of view about the role and place of democracy in the development of political processes in the world, taking into account new socio - and ethnocultural challenges and prospects for elaboration of new thinking principles of political science at the present stage.

Keywords: new thinking; political research; international relations; internal politics; divergence of the political process; liberal democracy; neo-authoritarianism

INFORMATION ABOUT THE AUTHORS

\begin{tabular}{l|l} 
Kamyshanov Viktor I. & $\begin{array}{l}\text { E-mail: vik.ifpc@mail.ru } \\
\text { ORCID 0000-0001-6792-6236 } \\
\text { Cand. Sc. (Politics), associate Professor }\end{array}$
\end{tabular}

For citation: Kamyshanov V. I. Transformation of the justification of modern political processes at the national and international level: the challenge of time // Social'nye i gumanitarnye znanija. 2020. Vol. 6, No 3. P. $230-237$. (in Russ.) 


\title{
Трансформация обоснования современных политических процессов на национальном и международном уровне: вызов времени
}

\author{
В. И. Камышанов ${ }^{1}$
}

${ }^{1}$ Школа политических исследований ИОН, РАНХиГС, пр. Вернадского, 82, корпус 2, Москва, 119571, Российская Федерация

DOI: $10.18255 / 2412-6519-2020-3-230-237$

УДК 303.01

Научная статья

Полный текст на русском языке

В статье рассматриваются вопросы поиска новых направлений теоретического осмысления и практического обоснования современных политических процессов на национальном и международном уровне. На основе сравнения российского и американского подходов к оценке развития политической науки проводится линия на изучение перспектив их сопряжения и адаптации к новым условиям. Рассматривается необходимость применения отвечающих вызову времени подходов к разработке теоретических направлений современной политической науки, с определением критериев глубины трансформации структурных условий, а также факторов дивергентности этих условий, влияющих на изменение характера и формы политической власти в современном мире. Востребованность этого подхода подтверждается сравнительным анализом существующих оценок исследователей развития политических процессов на национальном уровне под воздействием новых вызовов политической стабильности как ключевого фактора глобальной безопасности. Перспективы выработки новых подходов соотносятся с кризисными явлениями в развитии международных отношений и формированием противоречий в дихотомии противостояние - взаимодействие. Это состояние определяет содержание рассматриваемых точек зрения о роли и месте демократии в развитии политических процессов в мире с учетом новых социо- и этнокультурных вызовов и перспективах выработки новых принципов мышления в развитии политологии на современном этапе.

Ключевые слова: новое мышление; политические исследования; международные отношения; национальный уровень; дивергентность политического процесса; либеральная демократия; нео-авторитаризм

ИНФОРМАЦИЯ ОБ АВТОРАХ

\begin{tabular}{r|l} 
Камышанов Виктор & $\begin{array}{l}\text { E-mail: vik.ifpc@mail.ru } \\
\text { Иванович }\end{array}$ \\
& $\begin{array}{l}\text { ORCID 0000-0001-6792-6236 } \\
\text { Кандидат политических наук, доцент кафедры политологии и } \\
\text { политического управления }\end{array}$
\end{tabular}

Для цитирования: Камышанов В. И. Трансформация обоснования современных политических процессов на национальном и международном уровне: вызов времени // Социальные и гуманитарные знания. 2020. Том 6, № 3. С. 230-237.

(C) Камышанов В. И., 2020

Статья открытого доступа под лицензией СС BY-NC-ND (http://creativecommons.org/licenses/by-nc-nd/4.0/) 
Современные политические процессы в мире вызывают к жизни обсуждение проблем их возникновения, взаимозависимости и перспектив развития. Поиск ответов на возникшие вызовы требует поиска адекватного теоретического осмысления и обоснования. Инициатива политологических чтений «Политическая наука в поисках нового мышления», состоявшихся 29 февраля 2020 года в РАНХиГС, отражает одно из направлений обсуждения этого вопроса.

Сложившийся к настоящему моменту кризис в отношениях между государствами и внутри государств вновь сводится к дихотомии противостояния и сотрудничества, имеющего как внешние факторы, так и внутренние причины.

В контексте этого процесса вопросы о характере и перспективах политических исследований поднимаются в статье А. Ю. Мельвиля «Выйти из “гетто": о вкладе постсоветских исследований/Russian Studies в современную политическую науку» [1]. Автор рассматривает проблему постсоветских и новороссийских исследований через призму демократии и демократизации, исходя из классического понимания становления демократии как формы управления в минувшем веке. Вместе с тем развитие этих процессов в современных условиях не может исследоваться в отрыве от все более широко признаваемого кризиса демократии как таковой и особенно ее доминирующей на североатлантическом пространстве формы - либеральной демократии.

Современный период политических исследований столкнулся с определённым нарушением логики развития мировой политической системы. Разрыв этой ценностной цепочки привел к возникновению политической и идеологической лакуны. В целом ряде исследований, которые носят дискуссионный характер, обсуждаются новые подходы к рассмотрению всей системы международных отношений и их экстраполяции на локальный уровень. Но решение этого вопроса одновременно ставит задачу и определения системы ценностей, на которую должно опираться национальное политическое мышление. В этом контексте А. Мельвиль отмечает: «Но при этом пока нет ни новой метатеории, ни крупных теоретических и методологических прорывов, способных дать качественно новые объяснения современного политического многообразия и его противоречий. Скорее, сегодня в мировой политической науке время своего рода теоретико-методологической “интерлюдии”, некоторой “заставки" между прошлыми и будущими “большими темами”, время проверки и приращения знания. Это время преимущественно индуктивных и эмпирических подходов, сравнения новых наблюдений с существующими обобщениями, углубления полученных выводов и подготовки новых»[1, с. 24].

Дискуссия о роли и месте демократии в развитии политических процессов имеет давнюю историю и тесно связана с определёнными историческими формациями. Для политической науки в России этот процесс в основном соотносится с постсоветским периодом, на что и обращает внимание А. Мельвиль в своей работе. Он отмечает: «Демократия и демократизация по определению сразу стали центральной темой постсоветских исследований, включая общую проблематику трансформации и перестройки систем советского типа. В теоретическом плане отправная точка здесь - вопрос о генезисе демократии, в свою очередь связанный с различными пониманиями роли так называемых структурных и “агентивных" факторов, т. е. объективных предпосылок и субъективных действий, иначе говоря, дилемма structure/agency, подход, отчасти вдохновленный работами Энтони Гидденса» [1, с. 26].

Оценивая состояние политической науки и ее взаимодействие в современных условиях, ряд исследователей исходит из того, что российская политическая наука вырастает из некоего обширного зарубежного опыта политической науки, которая существовала и развивалась в собственном политическом измерении до момента 
возникновения постсоветского политологического пространства. Такое разграничение по времени и пространству нарушает объективность понимания динамики развития российской политической науки и определения ее места в современной международной политологии.

Сегодня следует признать, что формирование научных взглядов на политические науки допостсоветского периода развивалось, с одной стороны, на встречно-параллельных курсах с международным сообществом: западная политология, объясняющая капиталистические принципы развития, и советская, основывающаяся на принципах коммунистической идеологии. С другой - как бы ни доказывалась несовместимость этих двух направлений - они были подвержены взаимному влиянию и следили за формированием политической научной мысли оппонента. Это было основой динамического развития политической науки, которая до момента возникновения постсоветской ситуации исходила из важности обеспечивать уровень политических исследований и решений, отвечающий требованиям стабильного и поступательного развития капиталистического общества, утверждения и распространения той самой либерально-демократической модели, что обеспечивала внешние факторы ее преимущества в соревновании двух политических мировоззрений.

Важность и эффективность конкурентности в политических исследованиях была подтверждена в процессе выработки политических решений по проблеме обеспечения международной безопасности и ядерного разоружения в условиях биполярного мира. Разработка теоретических концепций договорно-правовых решений и их апробация в дискуссиях разного уровня в вопросах безопасности в сфере политологического обеспечения политических решений имела важное значение для формирования принципов политического обеспечения общеевропейской безопасности на национальном и международном уровнях. Пример «Восточной политики» Вилли Брандта является наиболее ярким примером корреляции политической теории с политической практикой в достижении конечного результата в международных отношениях современного периода [2; 3].

А. Мельвиль акцентирует внимание на одном векторе исследований - постсоветском, отмечал, что он нестатичен и подвержен изменениям. Но столь же нестатична и подвержена изменением и вся политологическая наука. Это является следствием нарастания турбулентных процессов в мировой политике, которые генерируются прежде всего политической дивергентностью1 под влиянием именно западного политического мышления, которое через утрату своей внутренней стабильности разрушает как собственное политическое пространство, так и иные этнические и социальные политические культуры - ближневосточную, китайскую, африканскую.

В новых условиях российская политология рассматривает и анализирует процесс развития политических исследований в центростремительном измерении, опираясь на опыт и знания внешнего мира применительно к развитию российской политической науки и ее политической системы.

Такой подход можно признать оправданным для рассмотрения процессов формирования демократии на пространстве, которое охватывает европейскую политическую систему и производные от ее социальных, этнических и конфессиональных механизмов власти, охватывающую и Северную Америку в той форме, в какой она сформировалась как наследник британских и французских колониальных завоеваний в этой части мира. И если мы анализируем демократические процессы на этом

\footnotetext{
${ }^{1}$ Диверге́нция (от средневекового лат. divergo "отклоняюсь») - расхождение признаков и свойств у первоначально близких групп организмов в ходе эволюции: результат обитания в разных условиях и неодинаково направленного естественного отбора.
} 
пространстве, то следует принять во внимание, что в США и Канаде эта политическая система формировалась как обеспечивающая миграцию европейского населения на это географическое пространство, где афроамериканская составляющая стала учитываться лишь во второй половине XX века. При этом надо понимать, что Северная Америка жестко освобождалась для переселенцев от местного коренного американского индейского населения, имевшего иную политическую культуру, традиции и обычаи.

Зарубежные исследователи признают, что причина современного кризиса политического диалога кроется в ином времени и в других политических пространствах. Томас Райт из Института Брукингса, анализируя перспективы возвращения противостояния великих держав, отмечает, что в США остался неизменным подход к реализации своих внешнеполитических интересов, исходя из приоритетов внутренней политики. С учетом этого и определяются принципы продвижения «международного либерального порядка», который лежит в основе внешней политики США после Второй мировой воны. При этом Райт как бы вскользь замечает, что «американцы никогда не были особенно очарованы либеральным международным порядком»[4]. Но в этой оценке, особенно для республиканцев, и проявляются образы теневых, неподотчетных сил, контролирующих мир.

В этой связи возникает вопрос - а является ли внутренняя политика США либеральной? Почему в дискуссии о современном мире американские эксперты, обращаясь к проблеме авторитаризма, внедряют восприятие этого феномена как внешнего, не присущего США? Разве действия США во внешнем мире после окончания Второй мировой войны строились на основе либеральной концепции развития мира? Не вдаваясь в подробности причины разработки и осуществления плана Маршалла, достаточно посмотреть на пример отношений США даже с близкими им англосаксонскими союзниками, к которому обращается Райт [Там же].

Таким образом, если применить названные принципы к другим политическим пространствам, за пределами стран «классической демократии», то станет понятным, почему эти экспортируемые механизмы классической демократии в них функционировали при наличии либо жёсткого военного, либо мягкого финансово-экономического воздействия и периодически сменялись более авторитарными формами «реализации принципов демократии». Наиболее рельефным примером таких мутаций демократических механизмов является Латинская Америка, где авторитарные режимы время от времени преобразовывались в демократические, но при возникновении угрозы потери контроля над политическими и экономическими процессами в этих странах они вновь возникали как форма «демонтажа» неугодных демократических политических процессов. Достаточно обратиться к примеру «демократических переходов» в Латинской Америке в Чили (Альенде) [5], Аргентине (Перон) [6; 7], Венесуэле (Чавес) [8].

Другой формой реализации принципов политического давления в интересах США стало силовое внедрение демократии в иных этнокультурных условиях на Ближнем Востоке и в Южной Азии, прежде всего в Афганистане и Ираке.

Такой подход либерально-демократической системы к реализации своего доминирования привел к разрыву линейности развития политического процесса и глобальному кризису безопасности и стабильности.

Развитие политической науки постоянно рассматривается как производная от политических процессов, генерируемых в Соединенных Штатах. В современных условиях мы наблюдаем определенное торможение этого процесса. У американской политической мысли существует некая растерянность в определение современных трендов, формируемых под воздействием новых политических реалий в США, которые возникли с приходом к власти президента Трампа. 
В этих условиях американские политологи пытаются определить, какие проблемы необходимо преодолеть для понимания сути приоритетов американской политики, где достижение успеха США будет зависеть как от внутреннего развития страны, так и от ее действий за рубежом. Спецификой современного процесса является то, что Дональд Трамп, будучи ограничен собственной администрацией и принципом разделения властей, который он эффективно использовал в своих целях в процессе импичмента, не оставил сомнений в стремлении следовать своим личным предпочтениям. Его действия являются родственными по духу нео-авторитаризму. Эта характеристика подтверждается тем, что он неоднократно писал в твиттере и говорил о своем пренебрежении свободой прессы и верховенством закона [9; 12]. В американских исследованиях отмечается, что он мало заинтересован в защите свободного мира от авторитарных достижений. «Если оставить его на произвол судьбы, он пойдет гораздо дальше выстраивания партнерства с Россией Владимира Путина и разовьет свое мировоззрение до того, что высокопоставленный чиновник Белого дома описал как «нет друзей, нет врагов»[4].

В этом соревновании поиска моделей управления президент Соединенных Штатов вошел в противоречие с системой, действующей в стране, что и объясняет тот конфликт, который возник в политических элитах с приходом несистемного президента Д. Трампа. Его неурегулированность представляет собой вызов лидерству либерализма в глобальной политической системе, который требует своего быстрого ответа. В стремлении найти подходы к нему Томас Райт отмечает: «Это идеологический вызов, который затмевает все, с чем Соединенные Штаты сталкивались во время «холодной войны». Тогда коммунизм никогда не имел реальной политической тяги. Сегодняшний нео-авторитаризм стал вирусным. Мы не должны преувеличивать его позиции в Америке - подавляющее большинство республиканцев не разделяет идеологию президента, даже если они поддерживают его политически но этот вызов не ограничивается внешнеполитической ареной. Американцы должны понять, как сохранить свободу у себя дома, в условиях политических и технологических сдвигов, а также оттеснить своих великих соперников»[Там же].

Сходную оценку высказывают другие эксперты по внешней политике, которые с момента победы на выборах анализировали, «окажет ли президент США Дональд Трамп временное или длительное влияние на глобальную политику, и в частности, будет ли он фатально подрывать либеральный международный порядок - сеть многосторонних институтов и гарантий безопасности, которую США помогли построить и поддерживали после окончания Второй мировой войны. Однако в последнее время эти дебаты сместились к вопросу о том, действительно ли либеральный международный порядок когдалибо существовал или вместо этого он был риторическим украшением витрины, используемым для смягчения грубых граней того, что составляло гегемонию США» [10].

В этой связи следует согласиться с тем, что «феномен Трампа» (или трампизм как явление) - это симптом постамериканского мира, а не его причина. Таким образом, мир входит в формирование новой структуры глобального развития в виде 2,5-полюсного мира, где векторы сил влияния можно представить как треугольник, в котором стороны представляют США и Китай, а в основании лежит Россия и трансформирующаяся, уже не единая Европа с общим индексом 0,5. Именно эта политическая конфигурация влияет на содержание трансформации современного политического мышления и поиска новых решений современных политических проблем.

Это предопределяет существование различных векторов тяготения в развитии политической науки. На постсоветском пространстве их возникло несколько - к европейскому вектору развития, к североамериканскому вектору развития. Однако эти 
векторы ограничивают индивидуальные особенности развития анализа и политического мышления на этом же пространстве. Более того, возникающие в условиях глобализации и многополюсности в результате такого мышления, новые векторы не сочетаются с традиционным представлением о перспективах развития политической системы. Их появление ставит в повестку дня вопрос о том, не являются ли они признаками завершения линейного политического мышления с его фиксированным обоснованием в рамках традиционной политической системы координат и перехода к новому этапу, который допускает переход к нелинейности развития современных политических процессов.

В этих условиях необходимо эти новые тренды экстраполировать на те классические постулаты, которые А. Мельвиль выделяет как следующие [1, с. 25]:

- вопрос о предпосылках демократии и демократизации, в том числе в приложении к методологической дилемме, важной не только для сравнительной политологии, но и для многих социальных наук;

- общая проблема шансов авторитарной модернизации без демократических реформ;

- возможности и ограничители традиционного институционального подхода и его новых разновидностей применительно к постсоветской реальности;

- вопрос о роли государства, государственного строительства и state capacity применительно к условиям и исходам постсоветских трансформаций, включая фактор и проблему «плохого управления» (bad governance);

- типы и вариации постсоветского авторитаризма, включая гибридные режимы, их устойчивость и условия их воспроизводства;

- субнациональные измерения постсоветской политики, региональные политические процессы и режимы.

Одновременно необходимо понять, каким образом осуществляется обратная связь российской политической науки с внешним миром. Обращение к этой проблеме важно потому, что сегодня в рассмотрении вопроса о развитии политических процессов мы столкнулись с тем, что реальная политика и обеспечивающие ее политтехнологи обогнали теоретическую политологию и развиваются по траекториям, которые не получили ни объяснения причин их возникновения, ни научно обоснованных перспектив развития. Поэтому важность анализа А. Ю. Мельвиля в том, что он, обращаясь к состоянию политических исследований в России, ставит проблемы, которые сегодня выходят за рамки российской специфики и имеют центробежные, трансграничные векторы развития и являются естественным следствием разрушения однополюсной системы мира, кратковременно возникшей на переломе XX и XXI веков. Это коррелирует с высказанным в ходе подготовки слушаний тезисом T.А. Алексеевой о том, что «рассмотрение наиболее важных подходов к исследованию политических и международных процессов показывает, что восприятие новых постулатов неоклассической и пост-неоклассической картины мира в сфере познания политического сталкивается с изрядными трудностями» [11].

Именно поэтому актуальным в целях преодоления этих «трудностей» становится «переосмысление применительно к современным процессам классических трактовок демократии и демократизации, влияющих на наше мышление, где во главе угла стояли структурные, т. е. “объективные” факторы и обстоятельства, из которых демократия как бы органически “вырастает”» [1, с. 26]. Среди них:

- характер социально-классовой структуры;

- уровни экономического и социального развития;

- независимая социальная стратификация;

- национальное единство и идентичность и др. 
Эти факторы рассматриваются в качестве предпосылок sine qua non, обязательных условий вызревания демократии. Демократизация в этой логике представляет собой реализацию и воплощение этих структурных условий [1, с. 26].

Вместе с тем современный анализ требует учета и новых вызовов, влияющих на структурные элементы, определяющих процесс принятия решений в достижении вариативности демократической консолидации, которая может рассматриваться как необходимый институт преодоления кризиса либеральной демократии. Речь идет о таких проблемах современного развития, как:

- социальная стабильность;

- экологическая безопасность;

- энергетическая безопасность;

- информационно-цифровая безопасность;

- безопасность здоровья человека;

- вызовы в области межкультурных отношений;

- демографические диспропорции.

Таким образом, если изменяются базовые структурные условия в результате возникновения новых вводных, то, соответственно, подвергаются изменениям и механизмы реализации принципов демократии, что в определенной форме объясняет и причину кризиса доминирующей пока формы либеральной демократии. Из этого следует, что определение нового мышления в политической науке связано с определением критериев глубины трансформации структурных условий и характера факторов дивергентности этих условий, влияющих на перспективу изменения места и формы политической власти в современном мире.

\section{Ссылки / References}

1. Мельвиль А. Ю. Выйти из “гетто": о вкладе постсоветских исследований/Russian Studies в современную политическую науку // Полис. Политические исследования. 2020. № 1. С. 22-43.

2. Кашлев Ю. Б. Общеевропейский процесс: вчера, сегодня, завтра. М.: Международные отношения, 1990.181 с.

3. Кремер И. С. ФРГ: этапы восточной политики. М.: Международные отношения, 1986. 224 с.

4. Wright T. The return to great-power rivalry was inevitable. The Atlantic. 12.09.2018. URL: https://www.brookings.edu/opinions/the-return-to-great-power-rivalry-was-inevitable (дата обращения: 28.02.2020).

5. Кудачкин М., Борисов А., Ткаченко В. Чилийская революция: опыт и значение. М.: Политиздат, 1977. 206 c.

6. Ермаков Д. Н. Теория и практика перонизма (Историко-политологический анализ): дис. ... д-ра полит. наук : 23.00.02. М., 2004. 325 c.

7. Соболев К. О военном перевороте 1976 года в Аргентине // Красная весна. 10.09.2015. URL: https://rossaprimavera.ru/article/o-voennom-perevorote-1976-goda-v-argentine (дата обращения: 03.08.2020).

8. Бенедиктов К. История ненависти Уго Чавеса - приговор Соединенным Штатам // Правда.Ру. 30.11.2019. URL: https://www.pravda.ru/world/75208-chavez (дата обращения: 03.08.2020).

9. Lynch J. Trump on Free Speech and Freedom of the Press // Electronic Frontier Foundation. 19.12.2016. URL: https://www.eff.org/deeplinks/2016/12/trump-free-speech-and-freedom-press (дата обращения: 03.08.2020).

10. Grunstein J. Trump Is a Symptom of the Post-American World, Not Its Cause // World Politics Review. 01.08.2018 URL: https://www.worldpoliticsreview.com/articles/25337/trump-is-a-symptom-of-thepost-american-world-not-its-cause?utm_source (дата обращения: 28.02.2020).

11. Алексеева Т. А. Политическая наука в поисках нового мышления // Социальные и гуманитарные знания. 2020. Том 6. № 1. С. 6-11.

12. Trump Twitter Archivesearch. URL: http://trumptwitterarchive.com (дата обращения: 03.08.2020). 